\title{
Professional development in optics and photonics education
}

Judith Donnelly, Fenna Hanes, Nicholas Massa, Barbara Washburn

Judith F. Donnelly, Fenna D. Hanes, Nicholas J. Massa, Barbara R. Washburn, "Professional development in optics and photonics education," Proc. SPIE 4588, Seventh International Conference on Education and Training in Optics and Photonics, (28 May 2002); doi: 10.1117/12.468727

SPIE Event: Education and Training in Optics and Photonics 2001, 2001, Singapore, Singapore 


\title{
Professional development in optics and photonics education
}

\author{
Judith Donnelly $^{* a}$, Fenna Hanes ${ }^{* * b}$, Nicholas Massa ${ }^{* * * c}$, Barbara Washburn ${ }^{* * * * c}$, \\ ${ }^{a}$ Three Rivers Community College, ${ }^{b}$ New England Board of Higher Education, \\ ${ }^{\mathrm{c}}$ Springfield Technical Community College
}

\begin{abstract}
In recent years, several New England projects have promoted professional development and curriculum design in optics and photonics. Funded in part by the Advanced Technological Education (ATE) program of the National Science Foundation (NSF), these projects have prepared middle and high school teachers, college faculty and career counselors from more than 100 New England institutions to introduce fiber optics, telecommunications and photonics technology education. Four of these projects will be discussed here:

- The New England Board of Higher Education's (NEBHE) Fiber Optics Technology Education Project, (FOTEP) was designed to teach fiber optics theory and to provide laboratory experiences at the secondary and postsecondary levels.

- Springfield Technical Community College's Northeast Center for Telecommunications Technologies (NCTT) is developing curricula and instructional materials in lightwave, networking and wireless telecommunications technologies

- The Harvard-Smithsonian Center for Astrophysics project ComTech developed a 12-week, hands-on curriculum and teaching strategies for middle and high school science and technology teachers in telecommunications and focused on optical communication (fiber optics).

- NEBHE's project PHOTON is preparing middle, secondary and postsecondary instructors to introduce theory and laboratory experiences in photonics, including geometric and wave optics as well as principles of lasers and photonics applications.
\end{abstract}

Keywords: photonics, fiber optics, telecommunications, PHOTON, NEBHE, FOTEP, STCC, NCTT, TRCC, ComTech

\section{INTRODUCTION}

Since 1995, the New England Board of Higher Education (NEBHE), a nonprofit organization serving the six New England states (Connecticut, Maine, Massachusetts, New Hampshire, Rhode Island and Vermont), has spearheaded professional development training and curriculum development projects in the field of photonics technology education. Three projects and one regional center were designed and implemented in response to available data regarding the demand for and supply of individuals prepared to work in the growing photonics field.

A federal study conducted in 1995 by the Center for Occupational Research and Development found that approximately 350,000 photonics technicians were employed in the United States, and it was expected that approximately 740,000 photonics technicians would be needed by the year $2000{ }^{1}$

Yet, there are only three New England community-technical colleges training photonics technicians at the associate degree level: Three Rivers Community College (TRCC) in Connecticut, Massachusetts Bay Community College (MBCC), and Springfield Technical Community College (STCC), both in Massachusetts. In total, these institutions graduate fewer than 30 technicians per year. In addition, studies have shown that very few students choose physics as a high school science course. If this situation continues, the emerging field of photonics and the overall fields of engineering and technology will be out of reach for those students who enter college underprepared in science.

The purpose of each of the projects is to increase the number of middle, secondary and postsecondary institutions across the region offering photonics education. The Northeast Center for Telecommunications Technology focuses its work on telecommunications technologies. This paper will describe four projects, all funded in part by the Advanced Technological Education (ATE) program of the National Science Foundation (NSF). 


\section{PROJECT DESCRIPTIONS}

\subsection{Fiber Optic Technology Education Project (FOTEP)}

In 1995, through a three-year NSF-ATE grant, NEBHE began preparing high school teachers and college faculty from 48 different secondary and postsecondary institutions throughout New England to introduce fiber optics curricula into existing programs. Faculty participants receive detailed assistance in developing curricula, laboratories and related experiments to comply with their specific program needs.

Participating teachers were recruited through mailings to institutions throughout New England with departments/programs in Physics, Electronics, Computers and Communications. Special effort was made to involve women teachers/faculty as well as institutions serving high numbers of minority students. Composition of participating institutions in the project is shown in Table 1.

Table 1: FOTEP participating institutions

\begin{tabular}{|l|c|}
\hline Secondary Schools & 24 \\
\hline Two Year Colleges & 21 \\
\hline Four year Colleges & 2 \\
\hline Universities & 1 \\
\hline
\end{tabular}

To ensure relevance to both industry and education, the project was guided by an Advisory Board composed of high school teachers and community/technical and four-year college faculty. Business and industry representatives served as technical consultants and presenters in workshops, assisted in the development of laboratories, provided site visits and were guest speakers at the workshops. Participation from industry also was assured by including David Maack, (Director of Special Projects in Research and Development, Porta Systems Corp.) as a Co-Principal Investigator for the project.. Maack is now with JDS Uniphase.

The project commenced with a two-day introductory workshop offered at four community colleges throughout New England in the fall of 1995 and the spring of 1996. In these workshops, participants were introduced to the basic theory and applications of optical fiber and each teacher constructed and tested two multimode fiber optic jumper cables. Participants were provided with information on expectations for the remainder of the program, and each received a binder containing comprehensive notes on fiber optic technology plus a kit for fiber optic connectorization and testing valued at approximately $\$ 1500$.

During the course of the three-year program, each participating school and college received over $\$ 4000$ worth of equipment and supplies for teaching fiber optics and FOTEP participants' home institutions were required to make a $\$ 2,000$ equipment match. This allowed grant equipment dollars to be used more effectively and also was seen as a statement of commitment on the part of the participating institution. In one case, a local fiber optics manufacturer provided the matching funds for a school unable to appropriate them.

In July 1996, a five-day summer workshop was held at Wentworth Institute of Technology in Boston, MA. Participants were housed in Wentworth's dormitories, and workshops were held in the college's fiber optics and electronics laboratories. The workshop format was both lecture and laboratory, encompassing experiments in data transmission as well as opportunities to practice additional fiber optics handling skills. Maack, the Co-Principal Investigator, notes that it takes a long time before a person becomes the master of fiber stripping, cleaving, handling, polishing, termination and coupling. "We want students (that is, our future employees) not to be intimidated by fiber. What is required is a lot of hands-on practice."

Participants left the summer workshop with copious notes on fiber optic theory and applications as well as curricula for fiber optic and related courses. In addition, each received a unique apparatus for studying fiber optic parameters. The "xyz rotary" stage designed by consultant Elias Awad (now retired from Wentworth Institute of Technology) allows precision measurements of fiber separation (1 micron precision over a range of more than $3 \mathrm{~mm}$ in the $\mathrm{x}$ direction, and 10 micron resolution over nearly $3 \mathrm{~cm}$ in the $\mathrm{z}$ direction) and can be used to measure connector alignment losses and fiber numerical aperture.

During the 1996-1997 academic year, technical assistance was provided to each participant incorporating fiber optic curricula at their own institutions. This gave participants assurance that they were not "on their 
own" when technical or administrative problems arose, since project personnel were readily available by telephone or by email. On several occasions, site visits were also made to assist participants.

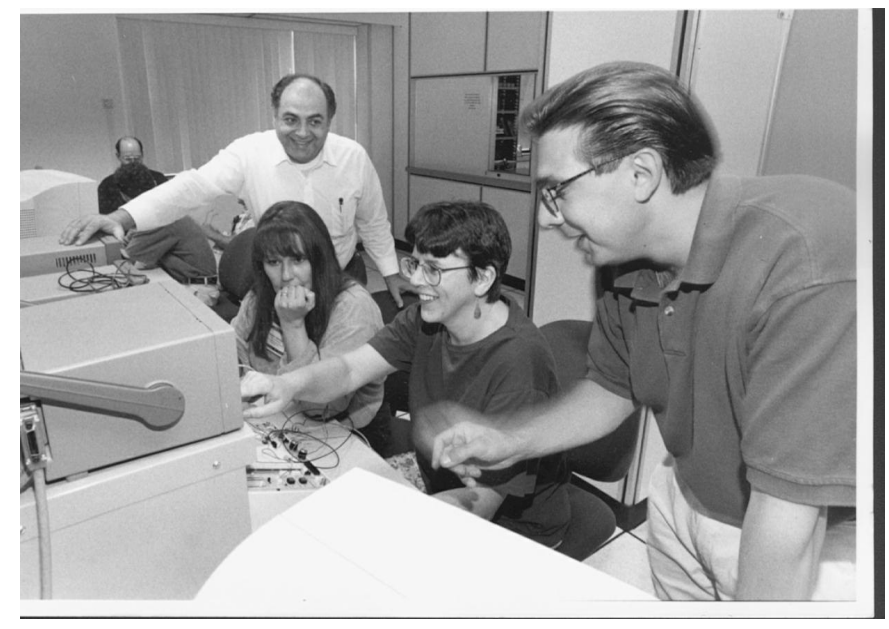

Figure 1 - Elias Awad and Nick Massa instruct FOTEP faculty participants in a fiber optic communications experiment

The final week-long workshop was held at Springfield Technical Community College in the summer of 1997. Advanced fiber optics communications topics were covered in both lecture and laboratory format. Because fiber optics technology is evolving rapidly, participants were updated on new trends and developments in the field. Again, technical assistance was available to participants throughout the ensuing academic year.

The FOTEP grant expired in June 1998. Based on annual status reports provided by the participants, 98 percent, or 47 schools, completed the program. Of the schools that completed the program, 94 percent are teaching fiber optics technology curricula ranging from units to courses to full degree programs. A new A.S. degree in Photonics Engineering Technology was developed by FOTEP participant Judith Donnelly at TRCC. Over the period of the grant, more than 4,300 students have had the opportunity to study fiber optics technology.

The FOTEP project made strong connections with industry, and many of these connections have been maintained by FOTEP participants as they teach fiber optics technology at their home institutions. The New England Fiber Optics Council (NEFC), an early FOTEP supporter, detailed FOTEP activities in its newsletter. FOTEP had an exhibit table at NEFC's first, second and third annual FiberFests, an industry trade show which attracted many FOTEP participants and their students. Industry guest speakers made presentations at both two-day and five-day workshops. Participants took field trips to NYNEX's (now Verizon) state-of-the-art training center, Galileo Electro Optics, SpecTran Fiber Optics (now Lucent), fc.com and Brooks Fiber. These businesses, plus numerous local companies contacted by participants, have remained supporters of fiber optics education.

Instructional materials developed by FOTEP and instructors from participating FOTEP schools played an important role in forming a basis for the lightwave component of the next NSF-ATE award of NCTT to STCC.

\section{Northeast Center for Telecommunications Technologies (NCTT)}

The Northeast Center for Telecommunications Technologies is one of eleven ATE Centers of Excellence funded by NSF. Baseline data had shown that very few associate or bachelor's degree programs in engineering technology in telecommunications technologies existed in New England and New York. In response to this deficit, in 1997, NSF awarded STCC a six-year grant to meet the growing demand for telecommunications technicians. The Center was an outgrowth of a number of previous activities, including a prior NSF grant to STCC in the field of telecommunications technologies, STCC's development and management of the NYNEX (now Verizon) Next Step associates degree program in telecommunications technologies in selected New England colleges, and the proposed leadership of NCTT by FOTEP Co- 
Principal Investigator James Masi. FOTEP Principal Investigator Nick Massa was the original Co-Principal Investigator for lightwave technology. Both Masi and Massa have left NCTT, and the former Co-Principal Investigator for networking technologies, Gordon Snyder, is currently Executive Director of the Center. Wireless technology is being directed by Co-Principal Investigator Gary Mullet and lightwave technology by Co-Principal Investigator James Downing.

The goals of NCTT are to:

- Develop a competency-based, industry-driven, seamless telecommunications curriculum including lightwave, networking and wireless technologies beginning in grade 11 through the associate degree and culminating in the bachelor of science in engineering technology or bachelor of science in engineering focused in telecommunications;

- write, pilot test and publish curriculum materials to improve telecommunications technology instruction and the underlying math and science principles which support it;

- develop alternative and state-of-the-art instructional delivery mechanisms (virtual laboratories, distance learning, synchronous and asynchronous learning, Internet courses, etc.)

- disseminate the curriculum, instructional materials and model programs regionally and nationally.

The Center employs a model of partnership. A network of approximately 30 partner high schools and colleges attends intensive professional development summer workshops where they work with the curriculum and instructional materials being developed by the NCTT technical directors. The materials are field tested during the subsequent academic year. Regional workshops are held during the academic year to provide technical assistance and provide opportunities for networking among the partner schools. Participating institutions are encouraged to develop articulation agreements between secondary and postsecondary institutions to create educational pathways for students. During the first three years of the project, partner schools came from the six New England states and New York. More recently, new partner schools from across the country have participated in workshops and Center activities. Since the Center's inception in 1997, more than 5000 students have received instruction in telecommunications technologies developed by NCTT.

Industry and government partners have provided a variety of support and technical assistance activities including:

- Participation in development of curricula and instructional materials.

- Internship opportunities that expose NCTT students to "real world" work-based experiences.

- Collaboration with industry and government in the development of work-based, college-level instruction both through distance learning and at industry sites.

- Participation on advisory committees.

Deliverables planned and available from the Center activities include;

- A high school telecommunications curriculum and instructional materials developed by and implemented at Minuteman Regional Vocational/Technical High School in Lexington, Mass. This material is currently available.

- A series of five telecommunications texts are under development. The networking and wireless texts are currently being field tested. Under development are texts on photonics, general telecommunications and advanced networking. A release date of Fall 2002 is anticipated.

- A series of skill competencies required in a telecommunications technologies curriculum have been developed and will be available on the NCTT website by year's end.

- A 1999 guide to associate degree and programs at vocational/technical high schools in New England and New York is available on the NCTT website, and a revised 2002 version will be available in print and on the website in early 2002.

- A CD entitled, "Careers in Telecommunications" is available

- Annual intensive summer workshops to disseminate instructional materials

- Semi-annual regional meetings to foster collaboration among partner schools

- Non-credit continuing education workshops for workers in the telecommunications programs are being offered.

- For further information, visit the NCTT website: www.nctt.org 


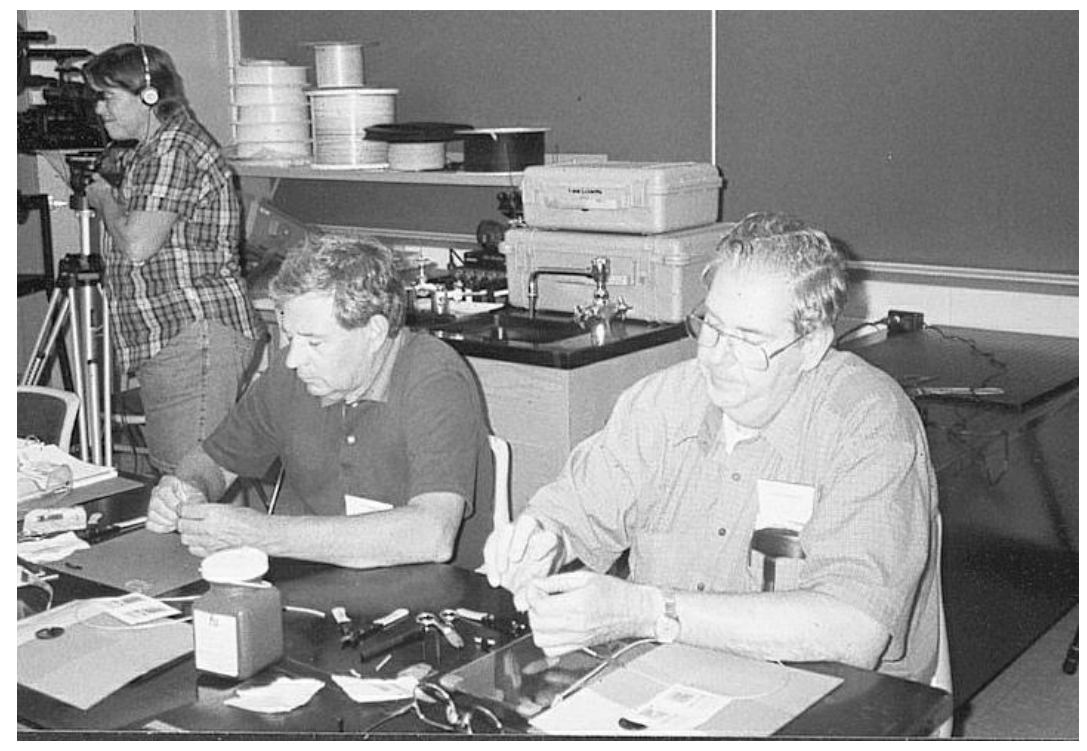

Figure 2 - Teachers practice terminating optical fiber at NCTT workshop

\subsection{Project ComTech: Light Communications: From Smoke Signals to Fiber Optics.}

Project ComTech was developed with funds from an NSF/ATE grant and additional support from Harvard University and the Smithsonian Institution. A team of five people from the Science Education Department at the Center for Astrophysics at Harvard University and Barbara Washburn, a faculty member who was at that time at Massachusetts Bay Community College, worked with 15 experienced Eastern Massachusetts technology education classroom teachers to develop the materials. The module was field tested with 22 separate classes and more than 500 students.

The two-year ComTech project began in January 1996. The module's written material was put in the form of a Teacher Resource Binder, consisting of four units comprising 25 innovative activities. The four units are:

- Introduction to communication systems

- Characteristics of light communication systems

- Improving communications using electronic components

- Optical fiber light communication systems

The Teacher Resource Binder contains extensive and detailed information for teachers, including technology principles for each lesson; historical information on the technology; descriptions and explanations of the technology and related science concepts in easy-to-understand terms; detailed lesson guides for each activity; career information related to technology; and suggested assessment strategies. Cross-curricular extensions relating to history, science, language arts, and science in society are also included along with relevant literature resources.

The ComTech activities lead students through a logical progression from primitive to sophisticated communication. Students first establish the context of the human need for communicating from one person to another. Primitive ways of communicating ideas or thoughts are introduced, including drumbeats and hand signals. These initial activities serve to provoke interest and stimulate curiosity. The need for a communications language, or code, arises when it is realized that words or thoughts, are hard to convey over a distance without breaking the information into smaller parts.

Once the need is established for a code, methods of sending the coded information are explored. Electronic (electric) communication over distance is introduced using the simplest of devices, a flashing light. Although a light can be seen over long distances, it becomes apparent that turning the light on and off in some organized way is necessary if the light is to convey information. Students build and use a simple switched circuit technology to solve this problem. They also learn about electric circuits in the context of a useful device. 
As a next step, students are asked to more carefully examine their communication system to see how it can be further improved. A new device, a "photo sensor," is introduced. Students learn that this new technology can improve communication, as the sensor is more responsive than the human eye to rapidly flashing lights. As a consequence, more information can be sent with the light beam. In the process of working with the photo sensor, students are introduced to transducers and several new electronic components, including a dc meter, loudspeaker, and a voltage to frequency converter.

In the final unit of the module, students construct a system that includes the use of a fiber optic cable as the medium that transmits the light to the receiver. The light is also converted to sound using a conversion circuit and a small microphone and speaker. This final unit makes a complete fiber optic communication system: the student can speak into the microphone, sound is converted into an electric signal, then converted into a light signal that is sent down the optical fiber. The fiber leads to a receiver where the photo sensor converts light into an electric signal which is then converted into a sound wave and transmitted over a speaker.

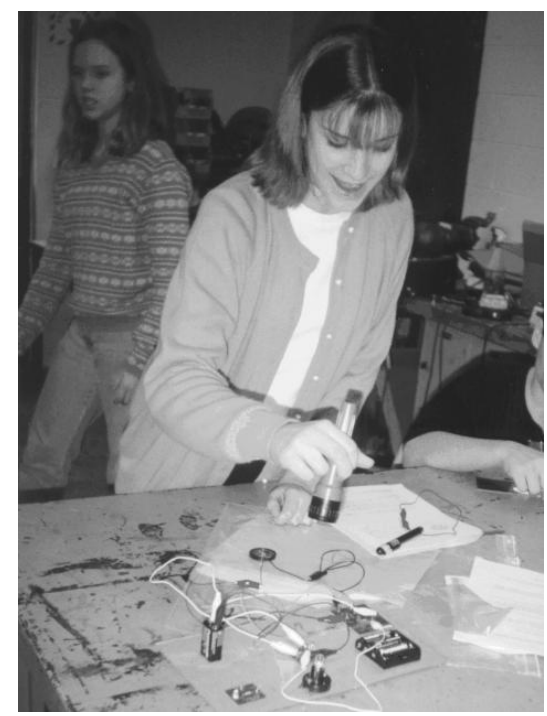

Figure 3 - Middle school student uses a flashlight and photo sensor in a ComTech activity

An external evaluator assessed project ComTech by using four evaluation methodologies:

- Telephone surveys of field test teachers

- Written survey of ComTech teachers

- Site visits by the evaluator to a random sample of field-test classrooms

- Summative evaluation of students learning using pre and post tests.

A sample of the results from the evaluator include:.

- $100 \%$ of the pilot teachers said the ComTech activities interested the students and held their attention.

- $100 \%$ reported that ComTech helped address state and national curriculum standards.

- $100 \%$ agreed that using ComTech materials increased students' knowledge of communication technologies.

- $90 \%$ of the teachers thought that the students were able to use ComTech materials to test their ideas about communication technology and science concepts.

The evaluator summarized the report by stating that the participating teachers gave ComTech activities a very high overall rating (mean of 4.6 on a 5 point Likert scale). All but one of the teachers indicated they would recommend ComTech to other teachers.

\subsection{Project PHOTON}

FOTEP initiated a strong curriculum and professional development model that brought together secondary and postsecondary instructors to gain experience and competence in introducing fiber optics to students in New England high schools and colleges. NCTT built on this model and began to focus on the need for instructional materials and professional development in the growing telecommunications industry. ComTech 
added the critical component of introducing middle school students to the use of light communications in technology education.

All these programs touched on photonics, but the focus was relatively narrow, covering only fiber optics and telecommunications. As the rapidly advancing field of photonics continues to have more applications, educators need to be exposed to these technologies so they can introduce them to their students. Yet few conceptual or applied instructional materials have been developed for the middle, secondary and postsecondary levels.

In response to the large and growing need for photonics technicians, and building on lessons learned from earlier projects, NEBHE and TRCC (a participating institution in both FOTEP and NCTT) proposed in 1999 to develop a curriculum and instructional materials, faculty enhancement and laboratory improvement project to be implemented regionally and serve as a model for national replication. The three-year proposal was funded by NSF and commenced in August 2000.

Project PHOTON is built upon the foundation of the first three projects detailed here (plus components from other successful NEBHE projects) and incorporates the best features and practices of the preceding activities.

The goal of PHOTON is to increase the number of middle, secondary and postsecondary institutions in New England with programs and laboratory resources required to prepare students for work in photonics. To accomplish this goal, project PHOTON has pursued several important objectives:

In order to increase the number of photonics programs, project PHOTON is:

- increasing the number of teachers who have the knowledge and expertise needed to teach photonics technology at the middle, secondary and postsecondary level

- educating high school career and guidance counselors and college placement staff about the many potential career opportunities in the emerging field of photonics

- developing and field-testing instructional materials

- providing participating institutions with industry quality laboratory equipment

To improve student interest and access to photonics programs, project PHOTON:

- increases the number of photonics lessons, courses and programs in middle schools, high schools and colleges

- reinforces classroom and laboratory learning with actual hands-on industrial applications

- prepares career/guidance/admissions counselors to introduce their students to career opportunities in the photonics industry

- recruits teachers and faculty from school systems with large minority populations

- collaborates with professional organizations of women and minorities in science and engineering

To increase educational alliances and opportunities for articulation and sustainability project PHOTON:

- supports educators from middle, secondary and postsecondary institutions in the same geographical locale to collaborate in professional development activities

- develops articulation agreements between secondary and postsecondary institutions

To enhance collaborative relationships with industry, project PHOTON:

- networks with individual companies and photonics industry professional associations

- designs industry-responsive programs

\subsubsection{Participants: The alliance model}

Implementing new instructional materials is a challenging task for teachers and faculty. Access to a support network of others working to achieve the same goals, referred to as an alliance, facilitates the change process. Alliances formed through project PHOTON provide the basis for collaboration resulting in future articulation agreements for an educational pathway for students. The alliances are also providing for dissemination of information to bring new educators into the network.

Through the alliances, participants are able to initiate articulated programs among the middle, secondary and postsecondary educational systems, leading students from high school to community college to four-year 
institution and university. A key goal for the project alliances is that they will be integrated into existing educational institutions and systems, so that the networks of teachers will remain viable once the program is completed.

A unique feature being incorporated in project PHOTON is the inclusion of career/guidance/admissions counselors in the workshops. Counselors, who have great influence over student decision-making, are being equipped with new knowledge for outreach to students interested in math, science and technology careers. Workshop programs were designed to meet career and guidance counselors' specific needs and interests.

\subsubsection{Project activities}

In order to ensure maximum participation by PHOTON participants, the project was conducted in two phases. The first phase, the Introductory Workshop, was designed to introduce approximately 120 New England teachers/faculty and career/guidance/admissions counselors to the field of photonics and to the scope of the PHOTON project so participants could evaluate whether their institution was prepared to make a three-year commitment to the project. These regional workshops also promoted networking to develop alliances among participants. Applications for the first workshop were solicited from middle schools, high schools and colleges throughout New England. Accepted schools were required to send both a teacher and a career/guidance/admissions counselor to the workshop.

Two PHOTON introductory workshops were held in November 2000. The first was hosted by Zygo Corporation (Middlefield, CT) and Three Rivers Community College (Norwich, CT), the second was hosted by Lucent Technologies (North Andover, MA) and the University of Massachusetts at Lowell. The first day of each workshop was attended by both teachers/faculty and career/guidance/admissions counselors and provided participants with industry, career and education information. The presentation included a photonics applications overview presented by Co-Principal Investigator John Swienton and an industry overview presented by Photonics Spectra magazine Executive Editor Stephanie Wiess. At each location, a career panel presentation, "What I do on the Job," featured a technician, an engineer, a sales and marketing representative and a human resources administrator from Zygo and Lucent respectively. An education panel composed of faculty members from New England colleges and universities discussed the state of photonics education nationwide. Each of the host companies provided a tour of its facilities to workshop attendees.

The second day of each workshop was for teachers/faculty only and was devoted to laboratory explorations and a technical introduction to optics and laser physics. The presentation began with a discussion of laser safety, and was followed by a curriculum overview of optics and laser principles. Participants performed hands-on activities with homemade ray boxes and gelatin-optics and used laser pointers to measure the thickness of a hair. Participants received Optical Society of America (OSA) Optics Discovery Kits, laser pointers and focusing flashlights. Using these materials, PHOTON instructors demonstrated several experiments for multiple grade levels.

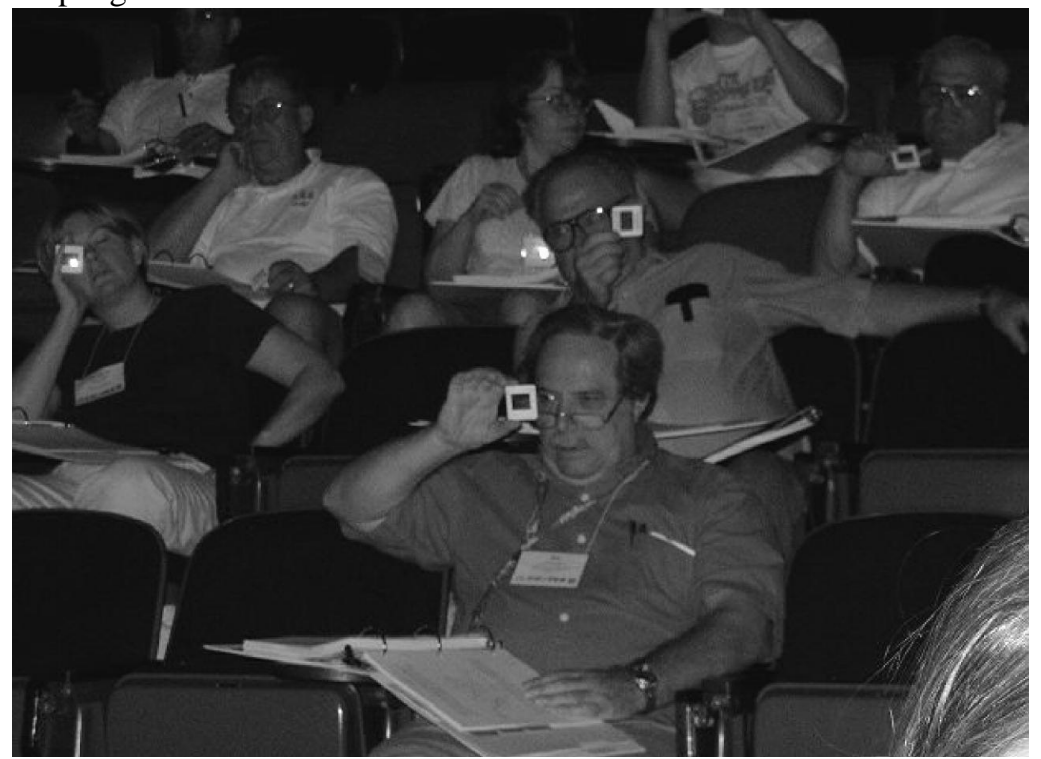

Figure 4 - PHOTON teacher participants observe light spectra through diffraction gratings during an introductory lecture 
Each participant was given a binder with complete notes on material covered during the workshop, including written instructions for the experiments performed. Thus, each teacher was given the means and curriculum to begin teaching optics immediately, at least at a very basic level. The PHOTON team described the laboratory equipment that each participating school would receive during the summer workshop, and the session concluded with state breakout sessions to begin forming alliances. Counselors were also provided a notebook containing information about careers in the photonics industry.

An evaluation of the workshops conducted by an outside evaluator from Boston College indicated that both workshops were highly rated by the participants. The average rating of both workshops was 4.57 out of a possible 5.00. The highest point (4.72) was given to the workshop notebook and other resources provided to the participants.

Because the PHOTON grant provided funding for only 40 institutions to participate in the summer workshops, down from the original 60 institutions that participated in the introductory workshop, a second competitive application was required. This process was intended to select one teacher/faculty member and one career/guidance/admissions counselor from each educational institution wishing to continue in the PHOTON project.

The 40 teacher/faculty participants chosen attended a one-week curriculum and professional development workshop held in July 2001 at STCC, which has one of the best-equipped community college photonics laboratories in the country. The teachers were joined by career/guidance/admissions counselors from their institutions for joint program held one evening. A dinner was followed by an Industry Partnerships Panel Presentation on work-based learning opportunities such as internships/externships, site tours, and speaker series.

The following day, a separate, concurrent program was held for career and guidance counselors. Topics covered in the "Career Development Strategies" workshop by panelists from middle, secondary and postsecondary institutions and industry included: infusing career development into academics; engaging students in technical careers; and marketing photonics to administrators and parents.

The topics covered during the weeklong teacher/faculty workshop are listed in Table 2 . The PHOTON team recognized that many of the teachers, particularly at the middle school level, were likely to have studied very little physics, so basic optics topics were covered as well as the more advanced laser and fiber optics applications.

Table 2: Topics covered during week-long teacher workshop

\begin{tabular}{|l|l|l|l|l|}
\hline Day 1 & Day 2 & Day 3 & Day 4 & Day 5 \\
\hline Nature of light & Superposition & Polarization States & Laser Safety & $\begin{array}{l}\text { Fiber Optics or } \\
\text { Laser Physics }\end{array}$ \\
\hline $\begin{array}{l}\text { Reflection and } \\
\text { Refraction }\end{array}$ & Coherence & $\begin{array}{l}\text { Production and } \\
\text { Modification of } \\
\text { polarized light }\end{array}$ & $\begin{array}{l}\text { Laser Physics } \\
\text { Ppplications of } \\
\text { Polarization }\end{array}$ & $\begin{array}{l}\text { Laser Materials } \\
\text { Processing }\end{array}$ \\
\hline Lenses/Mirrors & Interferometery & Holography \\
\hline $\begin{array}{l}\text { Applications of } \\
\text { Geometric Optics }\end{array}$ & Thin Films & Diffraction & & \\
\hline
\end{tabular}

The teacher workshop time was evenly divided between lecture/demonstration and hands-on laboratory experiences. At the conclusion of each day's activities, participants completed an evaluation form that included the opportunity to ask questions on the material covered during the day. Each day, Tuesday through Friday, began with the clarification of material from the previous day. In addition, requests for additional information on any topic (for example, additional material on laser physics) were entertained whenever possible. For example, the Friday morning session on laser physics was an ad hoc response to teacher requests. 
During the summer workshop, each participating institution received a custom-designed industrial quality optics laboratory kit and laboratory manual to be used in their own classrooms. Participants used the kit during the workshop, so that they would be familiar with it contents.

The PHOTON kit was designed to support the 18 experiments in the laboratory manual and was developed by the project team with the technical assistance of project Co-Principal Investigator John Sweinton, a sales engineer with Exfo America, Inc. An important feature of the laboratory manual is that the procedure for each experiment was actually tested using the PHOTON kit equipment by a team, ensuring that the lab experiments would actually work as intended during the workshop. In addition, suggestions for improvement from participants made during the workshop have been incorporated into the second draft of the laboratory manual.

The PHOTON kit was developed to demonstrate the fundamental optical and laser principles on which more advanced photonics applications can be based. The equipment is flexible enough, however, to allow many additional experiments to be performed. The equipment provided will allow one demonstration set-up of each of the experiments performed in the summer PHOTON workshop. Fifty percent of the cost of the $\$ 3,000$ equipment kit is covered by the NSF grant, the remaining $\$ 1,500$ is matched by the participating institution.

The PHOTON team made the decision to include components and component mounts of high quality, the type one might encounter in a research lab or in industry, rather than the more commonly encountered aluminum or plastic educational materials. Not only is the equipment more versatile than the "educational" variety, it is similar to equipment students will see on industry field trips, making the school laboratory experience more relevant to the world of work. The PHOTON instructors also provided advice on less expensive ways to outfit an entire classroom laboratory for schools unable (or not wanting) to replicate this particular kit. The contents of the PHOTON kit are listed in Table 3 and the kit itself is shown in Figure 5.

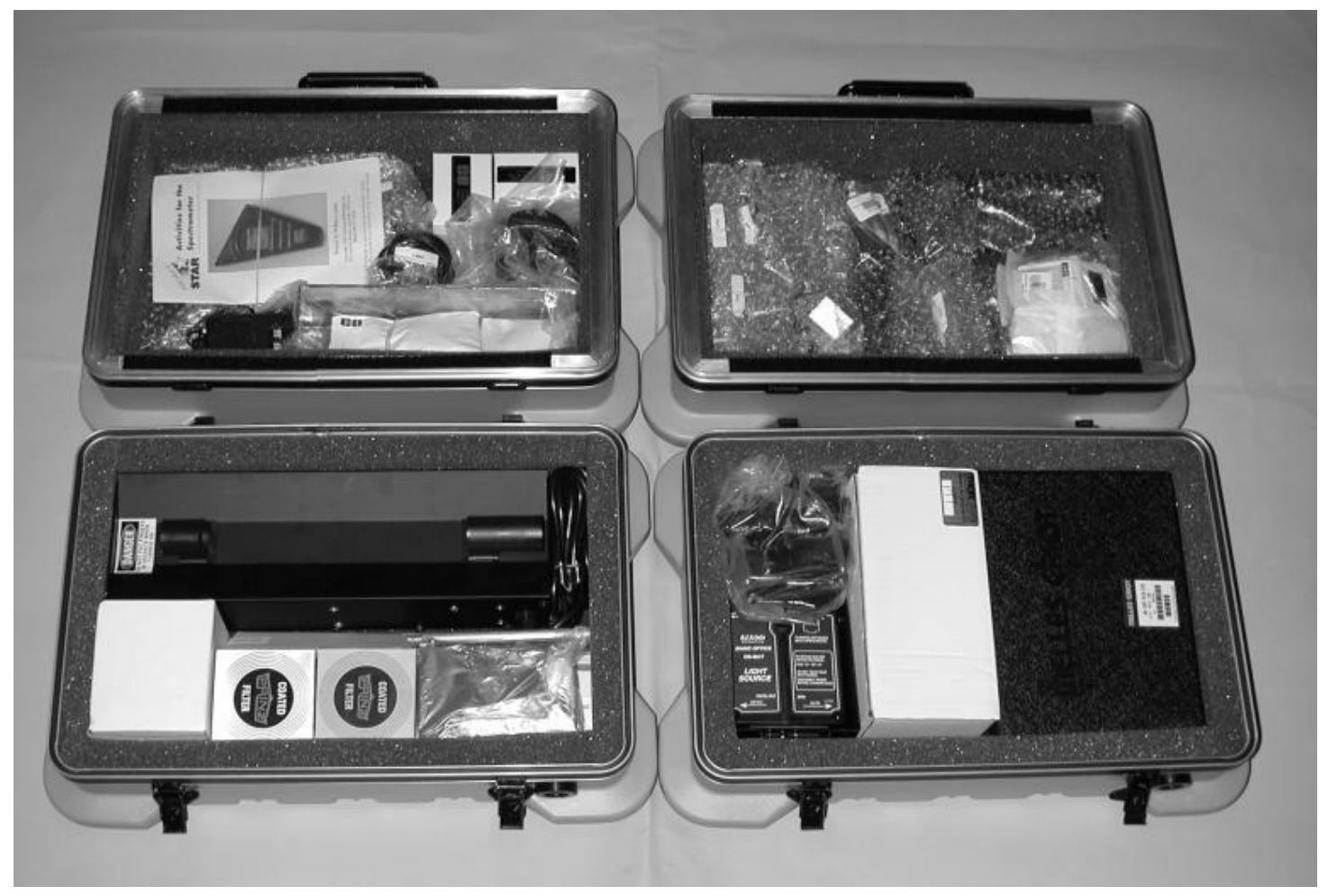

Figure 5 - The PHOTON kit 
Table 3 Detailed photon equipment list

\begin{tabular}{|c|c|c|c|}
\hline ITEM NAME & QUANTITY & ITEM \# & VENDOR \\
\hline $50 / 50$ cube beamsplitter, $25 \mathrm{mmx} 25 \mathrm{~mm}$ & 2 & L32-505 & Edmund Scientific \\
\hline broadband visible polarizing filters, $42 \mathrm{~mm}$ & 2 & L52-557 & Edmund Scientific \\
\hline spectrum tube power supply & 1 & L71-559 & Edmund Scientific \\
\hline H gas spectrum tube & 1 & L60-906 & Edmund Scientific \\
\hline He gas spectrum tube & 1 & L60-907 & Edmund Scientific \\
\hline laser tilt table & 1 & CP30089-01 & Cenco \\
\hline plate holder & 1 & FP01 & ThorLabs \\
\hline 2" lens holders & 4 & LMR2 & ThorLabs \\
\hline small base plate & 2 & BA1 & ThorLabs \\
\hline large base plate & 3 & BA2 & ThorLabs \\
\hline 1-axis translational stage, .05 inch travel & 1 & MT1 & ThorLabs \\
\hline HeNe laser, class IIIA, polarized & 1 & & Melles Griot \\
\hline 4 in 1 light source (ray box) & 1 & & Pasco \\
\hline bar type lens/filter holder, $70 \mathrm{~mm}$ & 2 & L03-669 & Edmund Scientific \\
\hline 1.5 "mount with front surface mirror & 2 & L33-498 & Edmund Scientific \\
\hline HeNe power meter & 1 & L54-038 & Edmund Scientific \\
\hline card mounted diffraction viewers & 20 & L50-183 & Edmund Scientific \\
\hline post holders, 2" and 3" & 4 each & $\mathrm{PH} 2$ and $\mathrm{PH} 3$ & ThorLabs \\
\hline post, 2" and 3" & 4 each & TR2 and TR3 & ThorLabs \\
\hline plastic refraction box & 1 & & Modern Plastics, Springfield, MA \\
\hline rotary mount assembly & 2 & K53-026 & Edmund Scientific \\
\hline prism mount hardware for item \#3 & 2 & L53-030 & Edmund Scientific \\
\hline mounted objective lens, $\mathrm{f}=8 \mathrm{~mm}$ & 1 & L45-045 & Edmund Scientific \\
\hline flat glass plate kit & 1 & & Cenco \\
\hline quantitative spectrometer & 1 & CP30105-00 & Cenco \\
\hline $\mathrm{CCV}$ mirror $50 \mathrm{~mm}$ dia $\mathrm{f}=75 \mathrm{~mm}$ & 1 & L52-462 & Edmund Scientific \\
\hline front surface plane mirrors $50 \mathrm{~mm} \times 50 \mathrm{~mm}$ & 4 & L52-324 & Edmund Scientific \\
\hline CVX mirror $50 \mathrm{~mm}$ dia $\mathrm{f}=-75 \mathrm{~mm}$ & 1 & L52-464 & Edmund Scientific \\
\hline CVX mirror $50 \mathrm{~mm}$ dia $\mathrm{f}=-100 \mathrm{~mm}$ & 1 & L52-465 & Edmund Scientific \\
\hline lens $50 \mathrm{~mm}$ dia $\mathrm{PCX} \mathrm{f}=100 \mathrm{~mm}$ & 2 & L52-240 & Edmund Scientific \\
\hline lens $50 \mathrm{~mm}$ dia $\mathrm{PCX} \mathrm{f}=200 \mathrm{~mm}$ & 2 & L53-100 & Edmund Scientific \\
\hline lens $50 \mathrm{~mm}$ dia DCX $\mathrm{f}=150 \mathrm{~mm}$ & 2 & L37-794 & Edmund Scientific \\
\hline lens $50 \mathrm{~mm}$ dia DCX f=250mm & 2 & L37-796 & Edmund Scientific \\
\hline lens $50 \mathrm{~mm}$ dia DCX f=50mm & 2 & L37-792 & Edmund Scientific \\
\hline lens $50 \mathrm{~mm}$ dia DCV f=-100mm & 1 & L37-800 & Edmund Scientific \\
\hline lens $50 \mathrm{~mm}$ dia $\mathrm{DCV} \mathrm{f}=-200 \mathrm{~mm}$ & 1 & L37-802 & Edmund Scientific \\
\hline $12 \mathrm{~mm} \mathrm{dia} / \mathrm{f}=6 \mathrm{~mm} \mathrm{ccv}$ spherical mirror & 1 & K43-462 & Edmund Scientific \\
\hline microscope objective holder & 1 & OMR & ThorLabs \\
\hline diffraction slits (single/double) & 1 & CP86205-00 & Cenco \\
\hline Iceland Spar Crystal & 1 & WL3558 & Cenco \\
\hline 1/4-20 socket head screws $1 / 2$ " & 20/kit & & ThorLabs \\
\hline 1/4-20 socket head screws 3/4 " & 20/kit & & ThorLabs \\
\hline 1/4-20 capscrews $1 / 2 "$ & 36/kit & & ThorLabs \\
\hline $8 / 32$ socket head screws $1 / 2 "$ & 20/kit & & ThorLabs \\
\hline hex key $1 / 8,3 / 16.3 / 32,5 / 64$ & 1 each & & ThorLabs \\
\hline bolt, washer, nut to attach laser to tilt table & 1 & & \\
\hline $\begin{array}{l}\text { 1/2 ' 2'x3' breadboard tapped 1/4-20 on 1" } \\
\text { Equipment Case }\end{array}$ & $\begin{array}{l}0 \\
2\end{array}$ & K03-679 & $\begin{array}{l}\text { Edmund Scientific } \\
\text { Diversified Case }\end{array}$ \\
\hline
\end{tabular}




\subsubsection{Advisory committee}

A national advisory committee composed of representatives from industry, education and professional societies was formed to guide principal investigators and senior personnel with recruitment, selection criteria, workshop and instructional materials development, dissemination and evaluation. The advisory committee reviews project plans and proposed curricula, advises the project team about the latest and most important trends in the photonics field, recommends ways in which the project can collaborate with industry to meet the need for skilled workers, and assists the project team in planning future directions and funding for PHOTON.

A subcommittee of the Advisory Committee has been exploring ways for PHOTON to collaborate with both SPIE and OSA through teacher professional development and the formation of high school "optics clubs" supported by both societies. PHOTON teachers have been offered free educational memberships in both societies, and a "suitcase" of educational and career related materials, available on loan to any PHOTON teacher, has been assembled by SPIE and OSA.

\subsubsection{Ongoing PHOTON activities}

During the 2001-2002 academic year, PHOTON instructors are providing one-on-one, electronic-based and on-site technical assistance. This strategy is designed to assist participating educators to implement photonics instructional materials into existing programs and develop laboratory exercises for hands-on activities. Teachers using the PHOTON materials will provide feedback from their classroom experiences which will be used to produce revised materials. Technical assistance is also being provided to career and guidance counselors via a listserve, a work based Careers in Photonics guide, and one-on-one and on-site visits.

A final two-day showcase workshop will be held in the spring of 2002. Teachers and counselors will be required to present a poster session describing the implementation of photonics technology education at their home institution. Selected participants will share implementation strategies through panel presentations. Guest speakers from industry will be invited to discuss technology trends in photonics.

Field tested instructional materials aligned to national science, mathematics and language arts standards will be available for distribution at the end of the project.

\section{FOTEP}

\section{ACKNOWLEDGEMENTS}

Funded in-part by the Advanced Technological Education program of the National Science Foundation (\#ATE 9553762). Principal Investigator, Nicholas Massa, Springfield Technical Community College, CoPrincipal Investigators Fenna Hanes (Project Manager), New England Board of Higher Education, James Masi, Western New England College, David Maack, (insert), Consultant Elias Awad

\section{NCTT}

Funded in-part by the Advanced Technological Education program of the National Science Foundation (\#ATE 9751990). Principal Investigator, Founding Principal Investigator, James Masi, (retired), Executive Director Gordon Snyder, , Co-Principal Investigators Nicholas Massa (returned to faculty assignments), Springfield Technical Community College, Fenna Hanes, New England Board of Higher Education,

\section{PHOTON}

Funded in-part by the Advanced Technological Education program of the National Science Foundation.(ATE \#ATE 0053284) Principal Investigator, Judith Donnelly, Three Rivers Community College, Co-Principal Investigators Fenna Hanes (Project Manager), New England Board of Higher Education, John Swienton, Exfo USA, Inc., Senior Personnel Nicholas Massa and Barbara Washburn, both Springfield Technical Community College

\section{COMTECH}

Funded in-part by the Advanced Technological Education program of the National Science Foundation (ATE \#9602404). Principal Investigator Philip Sadler, Harvard-Smithsonian Center for Astrophysics, CoInvestigators Irwin Shapiro, Harvard-Smithsonian Center for Astrophysics, Barbara Washburn, Massachusetts Bay Community College (Presently at Springfield Technical Community College), Associate Directors R. Bruce Ward and Paul Antonucci both Harvard-Smithsonian Center for Astrophysics 


\section{REFERENCES}

1 National Photonics Skills Standard for Technicians, Center for Occupational Research and Development, CORD, Waco, TX, 1995.

Contact:*jdonnelly@trcc.commnet.edu; Three Rivers Community College, 574 New London Tpk, Norwich, CT 06360; ** fhanes@ nebhe.org; New England Board of Higher Education, 45 Temple Place, Boston, MA 02111; ***massa@mail.stcc.mass.edu; Springfield Technical Community College, 1 Armory Square, Springfield, MA 01105; ****washburn@mail.stcc.mass.edu; Springfield Technical Community College, 1 Armory Square, Springfield, MA 01105 